\title{
RELATION BETWEEN SERUM ENZYMES AND LIVER HISTOPATHOLOGY IN MINK WITH HEPATITIS
}

\author{
A. Valdovska ${ }^{1,2}$, M. Pilmane ${ }^{2}$ \\ ${ }^{1}$ Faculty of Veterinary Medicine, Latvia University of Agriculture, Riga, Latvia \\ ${ }^{2}$ Institute of Anatomy and Anthropology, Riga Stradins University, Riga, Latvia
}

\begin{abstract}
The dystrophy of the mink liver is widely distributed in mink farms of Latvia. However, clinical diagnostics of the liver dystrophy is quite difficult. The hypothesis of this study was to clarify the indicators of ALT (alanine aminotransferase) and ALP (alkaline phosphatase) as the criteria in the early diagnostics of the mink liver injury. The goal of this study was to determine the potential correlation between the expressed functional indicators and the histopathology of the liver. Blood samples were obtained from ten minks, seropositive against the Aleutian disease. Liver injury was assessed histologically. Through application of the biotin-streptavidine immunohistochemical method, the presence of the hepatocyte growth factor, as well as the basal membrane components was established in the mink liver tissue, but liver apoptosis was determined by TUNEL. For the assessment of cytokines, a semi-quantitative counting method was used. The results showed the apoptosis of the hepatocytes in the whole area of the liver parenchyma. The correlation between the apoptosis and the expression of inflammation cells in the mink liver was non-existent. Constitutive release of cytokines (Hsp 70 and HGF) was detected in the liver hepatocytes centrilobular or around the periportal area. We established that have the mean correlation existed between the moderate steatosis and the weak HGF expression. Hsp 70 expression in hepatocytes was higher when moderate and numerous apoptotic cells were seen. The ALT level of the experimental mink in $40 \%$ cases was incresed above the standart. Interconnection between the degree of gravity of steatosis and the increasing of ALP and ALT levels was not found. We concluded that the simultaneous presence of the infiltration of inflammatory cells and the
\end{abstract}


moderate expression of $\mathrm{HGF}$ detect the still maintained regeneration ability of liver despite the persisting inflammation. The increased activity of liver enzymes (ALT and ALP) does not directly depend on the damaged mink liver disorders and can be suggested only as a common indicators for the liver disfunctioning of mink with the Aleutian disease.

Key words: mink, liver, blood, histopathology, the Aleutian disease.

\section{INTRODUCTION}

The liver is the largest metabolism centre and organ in the body. The disfunctions of liver can cause various reasons, one of them for mink is the Aleutian disease. The pathogenic agent (parvovirus) not only multiplies in macrophags, but suppresses CD8+ cells, stimulates plasmocitosis, and initiates the process of glomerulonepfritis and hepatitis $[9 ; 22]$.

Hepatocytes have several hundred functions and are a frequent target in infectious, toxic, metabolic and immunologic injury to the liver when injured, hepatocytes may produce and release oxygen free radicals, lipid peroxide products, proteases, cytokines and growth factors that injure adjacent cells [27]. It has been shown in numerous studies that cytokines are involved in the inflammatory syndrome and it may counterpart with the potential to limit an inflammatory response. The heat shock protein (Hsp) and the hepatocyte growth factor (HGF) are types of indicators of the cellular condition [8]. Liver function tests are a group of the biochemical measurements that are used to identify patients who are suffering from the liver or the biliary tract disease [18].

Although the liver has a great capacity for the regeneration of the hepatocyte mass [1], in the mink farms of Latvia the liver steatosis is widely distributed. Clinical diagnostics of the liver dystrophy is quite difficult. Reports of the relationship between the serum chemistry data and the liver morphology for mink are limited, therefore to establish the potential marker in serum as an early index for the morphopathology of liver were important. It made a choice of well timed methods of treatment. The hypothesis of this study was to clarify ALT (alanine aminotransferase) and ALP (alkaline phosphatase) as the criteria in the early diagnostics of the mink liver injury. The goal of this study was to 
determine the potential correlation between the expressed liver functional indicators and the histopathology of the liver.

\section{MATERIAL AND METHODS}

Animals and samples. To detect the histopathological changes in liver, 10 dark brown minks of seven months of age without clinical signs of any disease were randomly selected. All the mink were positive to the virus of $\mathrm{AD}$ according to the reaction of imunoelectroosmophoresis.

For obtaining of blood samples the mink were positioned on their back and heart puncture of animals was carry out [11]. Approximately 4 $\mathrm{ml}$ of blood was placed in the sterile vacutainer without anticoagulant. The blood samples for serum chemistry ALT (alanine aminotransferase) and ALP (alkaline phosphatase)) determinations in time of $2 \mathrm{~h}$ were sent to the National Diagnostic Center of Latvia and analyzed on the same day.

After parenteral euthanasia of mink with $1 \mathrm{ml} 1 \%$ solution of ditilini [11] their liver samples were fixed in $12 \%$ formalin. All the experimental minks were obtained within the period of pelting and slaughtering and in accordance with the guidelines of animal protection.

Immunohistochemistry. Multiple $6 \mu \mathrm{m}$-thick sections of the paraffinembedded mink liver were examined for immunohistochemistry [7]. Prior to immunostaining, sections were deparaffinized and rehydrated. Sections were processed in the microwave for $20 \mathrm{~min}$ in $4 \%$ citrate buffer $(\mathrm{pH} 10)$, quenched for 10 min with $3 \% \mathrm{H}_{2} \mathrm{O}_{2}$ for blocking endogenous peroxidase activity, rinsed in phosphate-buffered saline $(\mathrm{pH}$ $7,4)$, pretreated with a nonimmune goat serum for 10 min for blocking of nonspecific antibody binding and then incubated for $2 \mathrm{~h}$ with the primary antibodies.

The primary antibodies utilized in immunohistochemistry were rabbit polyclonal antibodies specific for the hepatocyte growth factor (HGF, dilution 1:300, R\&D System, DE) heat shock protein 70 (Hsp 70, dilution 1:100, abcam, UK). Immunoreaction was visualized by the avidin-biotin (LSAB) immunoperoxidase method using the LSAB kit (DakoCytomation, DK), and the DAB (diaminobenzidine) solution (Dako, DK) was used as chromogen, but hematoxylin - as the counterstain. 
TUNEL reaction was used for the detection of apoptosis [20]. In situ Cell Death Detection, POD (Roche Diagnostics) and the DAB substrate (Vector) were used. Deparafinised sections (xylol $2 \times 4 \mathrm{~min}, 99 \%$ ethanol $2 \times 2 \mathrm{~min}, 95 \%$ ethanol $2 \times 2 \mathrm{~min}$ and $70 \%$ ethanol $2 \times 2 \mathrm{~min}$ ) were rinsed with water (7-10 $\mathrm{min})$ and transferred to PBS (pH 7.5) for $10 \mathrm{~min}$. Subsequently slides were placed into $50 \mathrm{ml}$ PBS solution with $500 \mu \mathrm{l} 30 \%$ hydrogen peroxide for $30 \mathrm{~min}$ on shaker to block the endogenous peroxidases. Afterwards tissue samples were washed with PBS ( $3 \times 5 \mathrm{~min})$, placed into $0.2 \mathrm{M}$ boric acid $(\mathrm{pH} 7.0)$ and into the microwave $(700 \mathrm{~W})$ for $10 \mathrm{~min}$ for the fixation of antigen, cooled to room temperature and rinsed with PBS. After that, slides were kept in the refrigerator in $0.1 \%$ BSA (bovine serum albumin) solution with PBS for $10 \mathrm{~min}$ and then incubated in the TUNEL mix (Tdt - mix of terminal deoxynucleotide transferase and DIG-labeled deoxynucleotide) for $1 \mathrm{~h}$ at $+37^{\circ} \mathrm{C}$. Then the slides were rinsed with PBS 1:10, and incubated for 30 min at $+37^{\circ} \mathrm{C}$ with POD (sheep anti-digoxygenin antibogy coupled with horseradish peroxidase Fab fragment). Then the slides were washed with PBS, covered with DAB (diaminobenzidine chromogen) for 7 min, and rinsed with running water for 5 min. Finally, haematoxylin and eosin staining was performed on each sample. Sections were covered with a polystyrene-based medium and coverslipped.

Statistical analysis. For the quantitative analysis we used a counting of inflammation cells in three fields of vision, while the semi-quantitative analysis was used to estimate the proportions of immunopositive cells in liver [21]. The designations were as follows: 1 - few positive cells in the view field; 2 - moderate and 3 - numerous positive cells in the view field. For the statistical analysis (p-value) of the growth factor data the Wilcoxon rank tests were used.

\section{RESULTS}

Inflammation cells and cytokines in the mink liver. In the mink liver inflammation infiltrate, being rich in lymphocytes, was extending from the portal tracts towards the side parenchyma. In all the histological samples of the liver, macrophages constituted $18 \%$, neutrophil leukocytes $-27 \%$, but lymphocytes $-55 \%$ of the total inflammation cell count. A strongly marked tissue infiltration with macrophages, neutrophil leukocytes and lymphocytes was found around the central 
vein of lobuli, but the Kupffer cells infiltration - mainly around portal tract ducts.

In 10 minks, the liver histology and the TUNEL assay showed lesions and liver adaptive changes (Table 1). Fatty dystrophy was observed in all the mink liver samples, all the animals had mostly macrovesicular steatosis.

The results showed the apoptosis of the hepatocytes in the whole area of the liver parenchyma and the calculated statistical coherence shows that the influence of the inflammation cells on apoptosis is not significant $(p>0.05)$. In the cases of moderate [3] or numerous [2] apoptotic hepatocytes were seen, there was no considerable difference in the expression of inflammation cells, whereas when just a few [1] apoptotic cells were present, their number was considerably lower $(\mathrm{p}<0.05)$.

The constitutive release of cytokines (Hsp 70 and HGF) was detected in the liver hepatocytes centrilobular or around the periportal area. The expression of HGF and Hsp 70 was found in the zones, where lots of the inflammation cells were observed. The study revealed that numerous [3] positive apoptotic hepatocytes have the relationship $(\mathrm{r}=0.36)$ with a weak HGF expression and have the mean correlation $(r=0.59)$ between the moderate [2] steatosis and the weak HGF expression. We established that the Hsp 70 expression in hepatocytes was higher when moderate and numerous apoptotic cells were seen.

Serum enzymes. The results of biochemistry analysis are shown in Table 1. The ALT level of experimental mink in $40 \%$ cases was incresed above the standard, however, the level does not increase more than twice. Fatty distrophy was found in all the mink liver samples, however, the interconnection between the degree of gravity of steatosis and the ALT level was not found. The results showed that the increased ALT level correlated with the moderate apoptosis, but normal ALT level - with week and great apoptotic hepatocytes. Results also showed, that increased ALT level were when HGF expression was moderate [2], but normal ALT level were with weak and intense HGF expression (Figure1). 
Table 1. Cytokines in the liver and serum parameters of mink with hepatitis

\begin{tabular}{|c|c|c|c|c|c|c|c|}
\hline No. & $\begin{array}{l}\text { Infilt- } \\
\text { ration of } \\
\text { inflam- } \\
\text { matory } \\
\text { cells }\end{array}$ & $\begin{array}{l}\text { Fatty } \\
\text { dis- } \\
\text { trophy }\end{array}$ & $\begin{array}{c}\text { Apoptosis } \\
\text { of hepa- } \\
\text { tocytes }\end{array}$ & HGF & Hsp 70 & $\begin{array}{l}\text { ALT } \\
(\mathrm{U} / \mathrm{L})\end{array}$ & $\begin{array}{l}\text { ALP } \\
(\mathrm{U} / \mathrm{L})\end{array}$ \\
\hline 1. & 3 & 1 & 3 & 1 & 1 & 220.6 & 265.9 \\
\hline 2. & 2 & 2 & 2 & 3 & 0 & 89.9 & 139.6 \\
\hline 3. & 3 & 1 & 2 & 3 & 1 & 194.6 & 165.2 \\
\hline 4. & 3 & 2 & 2 & 3 & 0 & 87.4 & 119.4 \\
\hline 5. & 2 & 1 & 1 & 1 & 1 & 90.4 & 178.6 \\
\hline 6. & 2 & 1 & 3 & 1 & 1 & 116.2 & 194.1 \\
\hline 7. & 2 & 2 & 1 & 2 & 1 & 157.6 & 279.2 \\
\hline 8. & 2 & 1 & 2 & 2 & 0 & 182.6 & 188.5 \\
\hline 9. & 2 & 2 & 3 & 2 & 2 & 200.8 & 289.7 \\
\hline 10. & 2 & 1 & 3 & 1 & 1 & 117.8 & 197.1 \\
\hline \multirow{2}{*}{\multicolumn{5}{|c|}{ Standard }} & $\begin{array}{c}\text { Hunter, } \\
\text { Lemieux, } \\
1996 \\
\end{array}$ & $\begin{array}{l}\text { up to } \\
158.0\end{array}$ & $37-67$ \\
\hline & & & & & $\begin{array}{c}\text { Weiss } \\
\text { et al., } 1994\end{array}$ & $71.6-80$ & \\
\hline
\end{tabular}

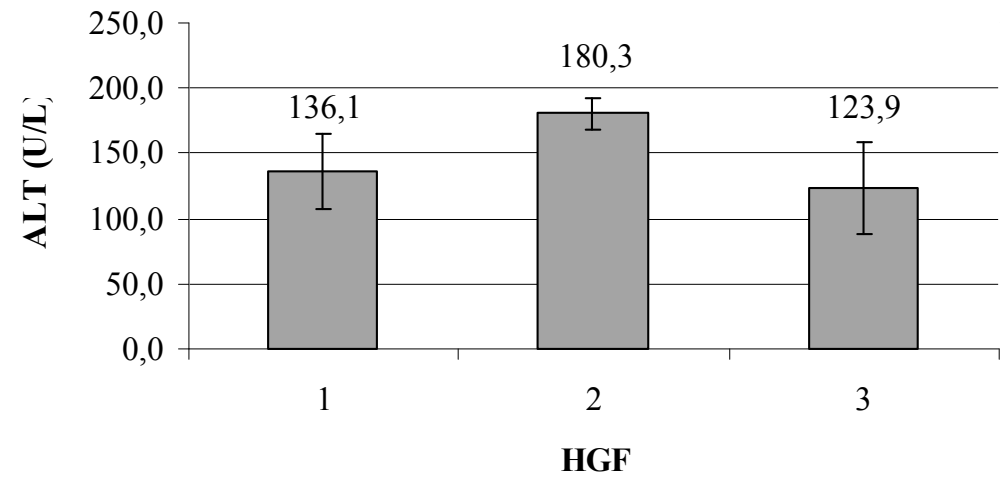

Figure 1. Relation between serum ALT level and HGF in mink liver. 
Blood serum ALP level (Table 1) was increased of all mink serum (119.4 - 289.7 U/1), however in general interconnection between degree of gravity of steatosis and increasing of ALP level were not founded.

\section{DISCUSSION}

The cellular, biochemical and molecular mechanism, that cause injury of hepatocytes play a role in all liver diseases [28]. In liver samples we basically observed that the lobule architecture has been maintained, but inflammation infiltrate which were rich with lymphocytes indicate to the pathological process. As usually only few lymphocytes can be found around the triad [12] then authors [17] characterize such a picture as a chronic and active hepatitis.

Upon comparing distribution of inflammation cells, lymphocytes showed the larges distribution. In liver parenchyma neutrophil leukocytes were about $28 \%$ less than lymphocytes, that can to take for significan index of functional condition of liver. Authors [12] confirm that infiltration of neutrophil leukocytes is observed in case of hepatitis and this is a proof of a perenchymal infection.

Apoptosis is genetically determined self annihilation mechanism, which is influenced by different condition [23]. In the study we observed apoptosis of hepatocytes in liver of mink in all parts of parenchyma although physiologicallly the apoptotic process is basically going in central vein area, which means that hepatocytes are developing in acinus 1 (periportal) section of liver and slowly migrates to area 3 (centrolobular) where they are degenerating [12;23].

Apoptosis may also develop without inflammation reaction [6]. As the results obtained did not show correlation between apoptosis of hepatocytes with infiltration of inflammation cells, we consider that there is some other reason, which causes apoptosis. Researchers [12; 26] assert that such a process is characteristic for viral infections as in the result of a combined effect of caspases activity and damage of cell mitochondrion, when the ferment endonucleases and a internucleosomal fragmentation of DNS is involved. This small number of apoptotic hepatocytes can possibly be explained by the presence of Aleutian disease virus persisting in mink organism, who can prevent the apoptotic process by inhibiting nuclear protein $\mathrm{p} 53$ and caspases, which damage cell DNA [23]. 
Hepatocyte growth factor (HGF) in normal hepatocytes persists in a non active form $[4 ; 10 ; 19]$, but in case of liver damage it is transformed in to active form [16]. Finding of positive coherence between moderate steatosis and HGF expression indicate to ability of mink liver regeneration. It can explain with fact, that HGF is an adipokine which stimulates cell division, motility, angiogenesis, and normal morphogenesis in injured tissue [29].

The release of cytokine Hsp 70 in liver zones, where lots of the inflammation cells were observed, indicated about Hsp as a type of indicator of the cellular condition [8]. Hsp 70 may constitutes an intracellular counterpart to proinflammatory cytokines with the potential to limita $\mathrm{n}$ exaggerated inflammatory response [5]. Our establishing, that Hsp 70 expression in hepatocytes was higher when moderate and numerous apoptotic cells were seen is similar to other authors [13] finding, that Hsp 70 is highly protective against oxidative stress and apoptosis. The mechanism by which Hsp 70 inhibits apoptosis has been well studied. There is abundant evidence that Hsp 70 inhibits events upstream of caspase- 3 and binds to the apoptotic-protease-activating factor- 1 and prevents the recruitment of procaspase- 9 to the apoptosome $[2 ; 15 ; 24]$.

Serum enzymes. An initial step in detecting liver damage is a simple blood test to determine the presence of certain liver enzymes in the blood. Among the most sensitive and widely used liver proteins are ALT and ALP. In our study interconnection between degree of gravity of steatosis and ALT level were not founded and it agree with results of other scientists [29]. Therefore, we speculate that the different ALT level are caused by an association with cellular membranes of apoptotic cells, it explains why apoptotic hepatocytes release ALT upon apoptosis induction [25]. It enable to conclude that ALT level increased in cases of acute hepatocyte injury [18]. Also HGF activity were increased, because in case of liver damage it is transformed in to active form [16].

ALP is liver protein that associated with structures of liver cells membrane. It is a hydrolase enzyme responsible for removing phosphate groups from many types of molecules, including nucleotides, proteins and alkaloids [14]. In all mink blood samples ALP level was increased. Mean increasing of protein can establish in cases of acute hepatitis [18], when bile ducts are blocked [3], but threefold ALP level testify about liver steatosis [31]. 


\section{CONCLUSION}

Simultaneous presence of infiltration of inflammatory cells and moderate expression of HGF detect the still maintained regeneration ability of liver despite the persisting inflammation. The increased activity of liver enzymes (ALT and ALP) do not directly depend on damaged mink liver disorders and can be suggested only as a common indicators for liver disfunctioning of mink with Aleutian disease.

\section{REFERENCES}

1. Aughey E., Frye F.L. (2001) Comparative veterinary histology with clinical correlates. Manson Pub. Ltd, London, 14-127.

2. Beere H.M., Wolf B.B., Cain K., Mosser D.D., Mahboubi A., Kuwana T., Tailor P., Morimoto R.I., Cohen G.M., Green D.R. (2000) Heat shock protein 70 inhibits apoptosis by preventing recruitment of procaspase-9 to the Apaf-1 apoptosome. Nat Cell Biol, 2, 469-475.

3. Coleman J.E. (1992) Structure and mechanism of alkaline phosphatase. Annu Rev Biophys Biomol Struct, 21, 441-83.

4. Defrances M.C., Wolf H.K., Michalopoulos G.K., Zarnegar R. (1992) The presence of hepatocyte growth factor in the developing rat. Development, 116, 387-395.

5. Flohe S., Speidel N., Flach R., Lange R., Erhard J., Schade F.U. (1998) Expression of HSP 70 as a potential prognostic marker for acute rejection in human liver transplantation. Transpl Int, 11, 89-94.

6. Green D.R., Ree J.C. (1998) Mitochondria and 4. apoptosis. Science, 281, 1309-1312.

7. Hsu S.M., Raine L., Fanger H. (1981) The use 5. of antiavidin antibody and biotin-streptavidin peroxydase complex in immunoperoxidase technics. American Journal of clinical pathology, 75, 6, 816-821.

8. Hideaki A., Hideaki I., Kenji K., Yasuhiko S., Yohtarou T. (1994) Heat shock protein 70 in rat liver with necrosis and regeneration induced by thioacetamide. J Gastroenterol, 29, 293-298.

9. Hunter D.B., Lemieux N. (1996) Aleutian disease. In: Mink biology, health and disease. University of Guelph, Ontario, 61-69.

10. Ishikawa K., Masui T., Ishikawa K., Shiojiri N. (2001) Immunolocalization of hepatocyte growth factor and its receptor (c-Met) during mouse liver development. Histochem cell biol, 116, 453 - 462.

11. Jepsen O.R., Poulsen F.S., Jorgensen G. (1981) Collection of blood, sedation and anaesthesia in mink. Nordisk veterinaermedicin, 1, 9-13. 
12. Klatskin G., Conn H.O. (1993) Histopathology of the liver. Vol. 1. Oxford University Press, USA, 327.

13. Kuboki S., Schuster R., Blanchard J., Pritts T.A., Wong R.H., Lentsch A.B. (2007) Role of heat shock protein 70 in hepatic ischemiareperfusion injury in mice. Am J Physiol Gastrointest Liver Physiol, 292, G1141-G1149.

14. Kim E.E., Wyckoff H.W. (1991) Reaction mechanism of alkaline phosphatase based on crystal structures. Two-metal ion catalysis. $J \mathrm{Mol}$ Biol, 218, 2, 449-464.

15. Li C.Y., Lee J.S., Ko Y.G., Kim J.I., Seo J.S. (2000) Heat shock protein 70 inhibits apoptosis downstream of cytochrome c release and upstream of caspase-3 activation. J Biol Chem, 275, 25665-25671.

16. Ljubimova J.Y., Petrovic L.M., Arkadopoulos N., Blanc P., Geller S.A., Demetriou A.A. (1997) Lack of hepatocyte growth factor receptor (c-met) gene expression in fulminant hepatic failure livers before transplantation. Digestive Diseases and Sciences, 42, 8, $1675-$ 1680 .

17. Macsween R.N.M., Anthony P.P., Scheuer P.J. (1979) Pathology of the liver. Churchill Livingstone, New York, 23-205.

18. Mason P. (2004) Blood tests used to investigate liver, thyroid or kidney function and disease. The Pharmaceutical Journal, 272, 446-449.

19. Miyazawa K., Shimomura T., Kitamura N. (1996) Activation of hepatocyte growth factor in the injured tissues is mediated by hepatocyte growth factor activator. The Journal of Biological Chemistry, 271, 7, 3615-3618.

20. Negoescu A., Guillermet C., Lorimer P., Robert C., Lantuejoul S., Brambilla E., Labat-Moleur F. (1998) TUNEL apoptotic cell detection in archived paraffin-embedded tissues. Biochemica, 3, 36-41.

21. Pilmane M., Rumba I., Sundler F., Luts A. (1998) Patterns of occurrence and distribution of neuroendocrine elements in lungs of humans with chronic lung diseasess. Proceedings of the Latvian Academy of Sciences, 52, (596/597), 144-152.

22. Porter D.D., Larsen A.E., Porter H.G. (1973) 19. The pathogenesis of Aleutian disease of mink. American Journal of pathology, 71, 331-344.

23. Rubin E., Farber J.L. (1999) Inflammation. Pathology. 3rd ed. Lippincott-Raven, Philadelphia, 25-27.

24. Saleh A., Srinivasula S.M., Balkir L., Robbins P.D., Alnemri E.S. (2000) Negative regulation of the Apaf-1 apoptosome by Hsp70. Nat Cell Biol, 2, 476-483. 
25. Sass G., Soares M.C.P., Yamashita K., Seyfried S., Zimmermann W.H., Eschenhagen T., Kaczmarek E., Ritter T., Volk H.D., Tiegs G. (2003) Heme oxygenase-1 and its reaction product, carbon monoxide, prevent inflammation-related apoptotic liver damage in mice. Hepatology, 38, 909-918.

26. Schulte-Hermann R., Bursch W., Löw-Baselli A., Wagner A., GraslKraupp (1997) Apoptosis in the liver and its role in hepatocarcinogenesis. Cell Biology and Toxicology, 13, 339-348.

27. Sokol R.J. (2001) Bile acid-induced rat hepatocyte apoptosis is inhibited by antioxidants and blockers of the mitochondrial permeability transition. Hepatology, 33 (3), 616-626.

28. Sokol R.L. (2002) Liver Cell Injury and Fibrosis. Journal of Pediatric Gastroenterology and Nutrition. 35, S7-S10.

29. Yasemin H.B., Hale S., Halis S., Durdal U., Gonca T. (2006) Metabolic syndrome, non-alcoholic steatohepatitis (NASH), and hepatocyte growth factor (HGF). Annals of Hepatology, 5(2), 109-114.

30. Weiss D.J., Wustenberg W., Bucci J.T., Perman V. (1994) Hematological and serum chemistry reference values for adult brown mink. Journal of Wildlife Diseases, 30, 599-602.

31. Willard M.D., Tvedten H., Turnwald G.H. (1994) Small animal clinical diagnosis by laboratory methods. $2^{\text {nd }}$ ed., W.B. Saunders, Philadelphia, $56-57$.

\section{Address for correspondence:}

Anda Valdovska

Faculty of Veterinary Medicine

Latvia University of Agriculture

Kabiles str. 44, Marupe, LV-2167, Latvia

E-mail: Anda.Valdovska@llu.lv 